\title{
Does the Location of the Cutting Flute of Self-Tapping Screws in Bony Substrate Affect the Removal Torque?
}

\author{
David James Chapman Graham ${ }^{1}$, Alistair Spiers ${ }^{1}$, Eric Swarts ${ }^{2}$, Colin Whitewood ${ }^{3}$ \\ ${ }^{1}$ Royal Perth Hospital, Perth, Australia \\ ${ }^{2}$ Department of Engineering and Medical Physics, Royal Perth Hospital, Perth, Australia \\ ${ }^{3}$ Princess Margaret Hospital, Perth, Australia \\ Email: ortho reg@yahoo.com
}

Received 29 November 2014; revised 15 December 2014; accepted 31 December 2014

Copyright (C) 2015 by authors and Scientific Research Publishing Inc.

This work is licensed under the Creative Commons Attribution International License (CC BY). http://creativecommons.org/licenses/by/4.0/

c) (i) Open Access

\begin{abstract}
Introduction: An observation was made that when removing self-tapping cortical screws from patients bones, stripping or shearing of the head of the screw occurred more often in screws whose cutting flutes sat in cortical bone compared with screws that had penetrated the distal cortex with flutes exposed. Method: A model was designed to simulate screws with their cutting flutes either in contact with cortical bone or deep to cortical bone. Screws were grouped depending on the location of their cutting flutes and removal torque was measured. Results: Eighteen screws were included in final analysis. There was a statistically significant difference in average initial removal torque and average maximal removal torque with screws with their cutting flutes in substrate requiring significantly more torque to remove. Conclusion: We conclude that self-tapping cortical screws whose cutting flutes sit in cortical substrate require more torque to remove and are therefore more likely to fail. This finding may be used as a guide in pre-operative planning for removal of metalwork from patients.
\end{abstract}

\section{Keywords}

Stainless Steel Screws, Removal Failure, Metalwork Removal, Self-Tapping Screws

\section{Introduction}

Metal screws are widely used in orthopaedic operations in both the elective and trauma setting. Most of these

*Corresponding author.

How to cite this paper: Graham, D.J.C., Spiers, A., Swarts, E. and Whitewood, C. (2015) Does the Location of the Cutting Flute of Self-Tapping Screws in Bony Substrate Affect the Removal Torque? Open Journal of Orthopedics, 5, 1-5. 
screws are machine screws with uniform thread and blunt tips which are placed in a pilot hole [1]. The standard insertion technique is to drill a pilot hole slightly wider than the root diameter of the screw and use a hand tap to cut a reciprocal thread. The reciprocal thread reduces friction during screw insertion while the flutes of the tap allow reamed material to be channelled away from the tip of the screw.

Self-tapping screws cut their own reciprocal thread as they are advanced obviating the need for a separate tap after drilling. Self-tapping screws are either thread-forming (cancellous) or thread-cutting (cortical). Threadforming screws have no cutting flutes, produce little debris and compact the receiving bone. Thread-cutting screws have sharp flutes at the tip which cut a channel for the screw and remove debris [2]. Insertion torque is higher for self-tapping screws but operative time is reduced when compared with tradition drill, tap, and screw insertion technique [3]. Once the depth of the pilot hole is measured, the surgeon must decide on screw length which can either be the same as measured, or slightly longer, depending on screw length availability.

Although removal of metalwork is not a recommended routine procedure [4], it is commonly undertaken especially in the paediatric population [5]. Complications associated with metalwork removal can be disabling. The literature for the paediatric population shows an overall complication rate of 14 percent with half of those being retention of the distal part of broken screws [6].

At our institution along with others [7], removal of screws from proximal femoral osteotomy plates is routinely undertaken at 12 months. Occasional stripping or shearing of the head of self-tapping cortical screws during removal of metalwork was observed and was most likely to occur in screws whose cutting flutes sat in cortical bone rather than with screws that had penetrated the distal cortex with flutes exposed.

On the basis of these observations, a model was designed to test whether location of the cutting flute of self-tapping screws in bony substrate affected the removal torque and therefore the chance of screw breakage during removal.

\section{Method}

The model was designed to simulate screws with their cutting flutes either in contact with cortical bone or deep to cortical bone. Twenty identical self-tapping, thread-cutting (cortical) screws were tested. Screws were manufactured by Smith and Nephew (Smith and Nephew Inc., 1450 Brooks Road, Memphis, Tennessee, USA) and thread diameter was $4.5 \mathrm{~mm}$. A Teflon tray was constructed with 10 smooth pre-drilled recesses in the base and a metal rack above from which screws could be suspended. The tray was designed to be dismantled so as not to disturb the cast during extraction (Figure 1).

Screws were arranged in two groups of ten screws. Group A were placed into the pre-drilled holes in the Teflon base so cutting flutes were not exposed to cement. Group B were suspended from the metal rack so the flutes were set in cement and the tips rested against the Teflon base. The tray sat on a level surface at standard room temperature. Zimmer low viscosity cement (Zimmer P.O. Box 708, 1800 West Center Street, Warsaw, IN, USA)

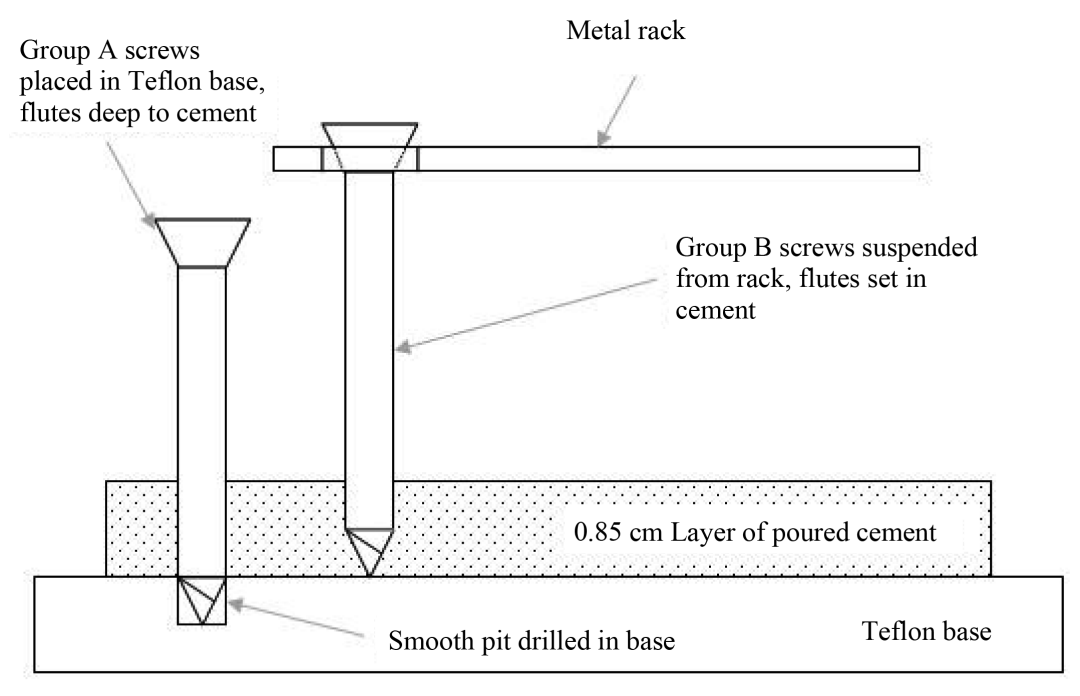

Figure 1. Diagram of arrangement of two screw groups in cement. 
was used to represent cortical bone and was poured around the screws to a depth of $0.85 \mathrm{~cm}$ and allowed to harden for 3 hours.

After setting the tray was disassembled and the cement cast containing the screws was recovered. A vernier calliper was used to measure cement depth. One screw from group A was removed due to cement leaking into flutes and one non-uniform screw from group B was removed leaving eighteen screws available for testing. A torque-measuring machine was applied to screws which were removed by turning. Initial and maximal torques were recorded. Screws were also inspected after removal.

Statistical analysis was performed using Graph Pad Software (Graph Pad Software Inc.) applying t-test to calculate the exact $\mathrm{P}$ value. A $\mathrm{P}$ value $<0.05$ was regarded as significant.

\section{Results}

Results from all tested screws are presented in Figure 2. Cement depth from vernier calliper measurements varied between $0.80 \mathrm{~cm}$ and $0.97 \mathrm{~cm}$. Average depth for group A screws (cutting flutes deep to cement) was 0.85 $\mathrm{cm}(\mathrm{SD} 0.016 \mathrm{~cm})$ and group B screws (cutting flutes in cement) was $0.89 \mathrm{~cm}(\mathrm{SD} 0.038 \mathrm{~cm})$. This was calculated to not be statistically significant ( $\mathrm{P}$ value 0.28 , $\mathrm{CI}-0.09$ to 0.03 ). Average initial ( 0.25 seconds) torque was $0.93 \mathrm{Nm}($ SD $0.34 \mathrm{Nm})$ for group A screws and $3.2 \mathrm{Nm}(\mathrm{SD} 0.93 \mathrm{Nm})$ for group B screws. This was a statistically significant difference ( $\mathrm{P}$ value $<0.0001)$. Average maximal torque was $1.62 \mathrm{Nm}(\mathrm{SD} 0.29 \mathrm{Nm})$ for group A screws and $3.7 \mathrm{Nm}(\mathrm{SD} 0.35 \mathrm{Nm}$ ) for group B screws which is statistically significant (P value < 0.0001 ) (Figure 2).

Screws in group A and B displayed markedly different patterns in removal torque. In group A screws torque rose rapidly to overcome the resistance of thread in the cement. The rate of increase then slowed until maximal torque was reached later in the revolution. Group B screws demonstrated a different pattern with a rapid rise to maximal torque in the first quarter of a second before decreasing rapidly (Figure 3).

No screws had any sign of head stripping or shearing. No group A screws had cement in the cutting flutes. A significant amount of cement remained in the cutting flutes of group B screws (Figure 4).

\section{Discussion}

The experiment was designed to test the hypothesis that self-tapping screws whose cutting flutes sit in cortical bone are more difficult to remove, and thus are more prone to shearing, than screws that have penetrated the distal cortex. The model showed that the removal torque varied significantly depending on the location of the flutes of self-tapping screws relative to the cement and confirmed the initial observation that screws with cutting flutes in contact with cement are more difficult to remove.

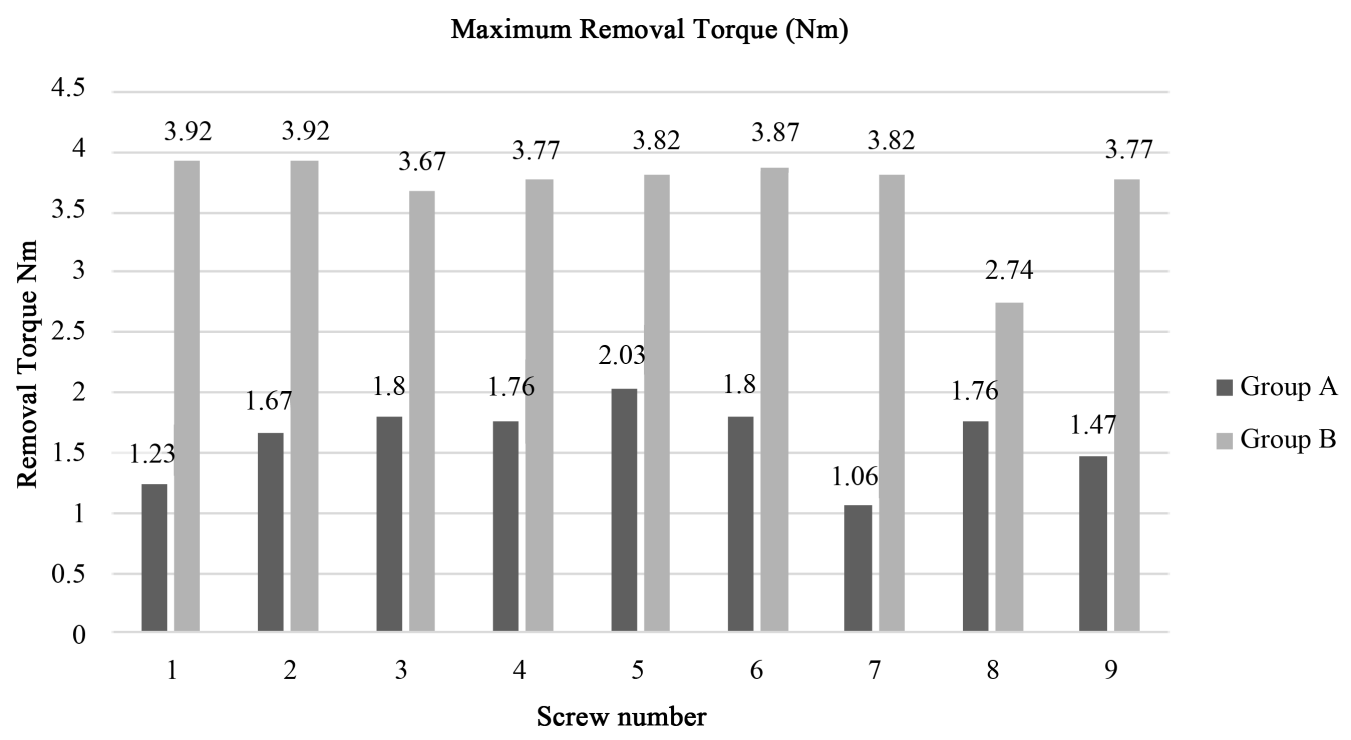

Figure 2. Maximal removal torque group A and B screws. 


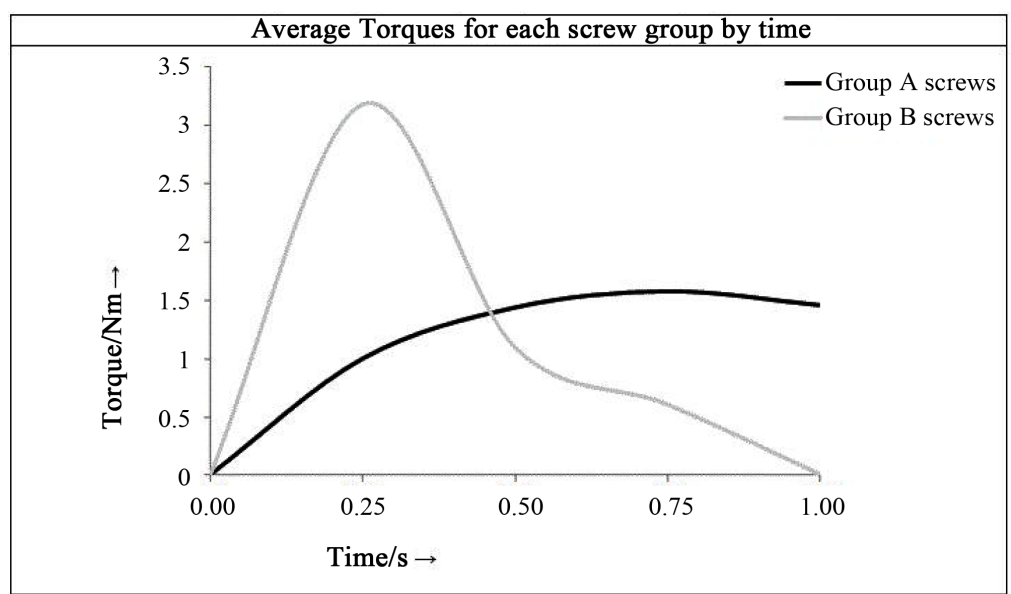

Figure 3. Average torque for each screw group by time.

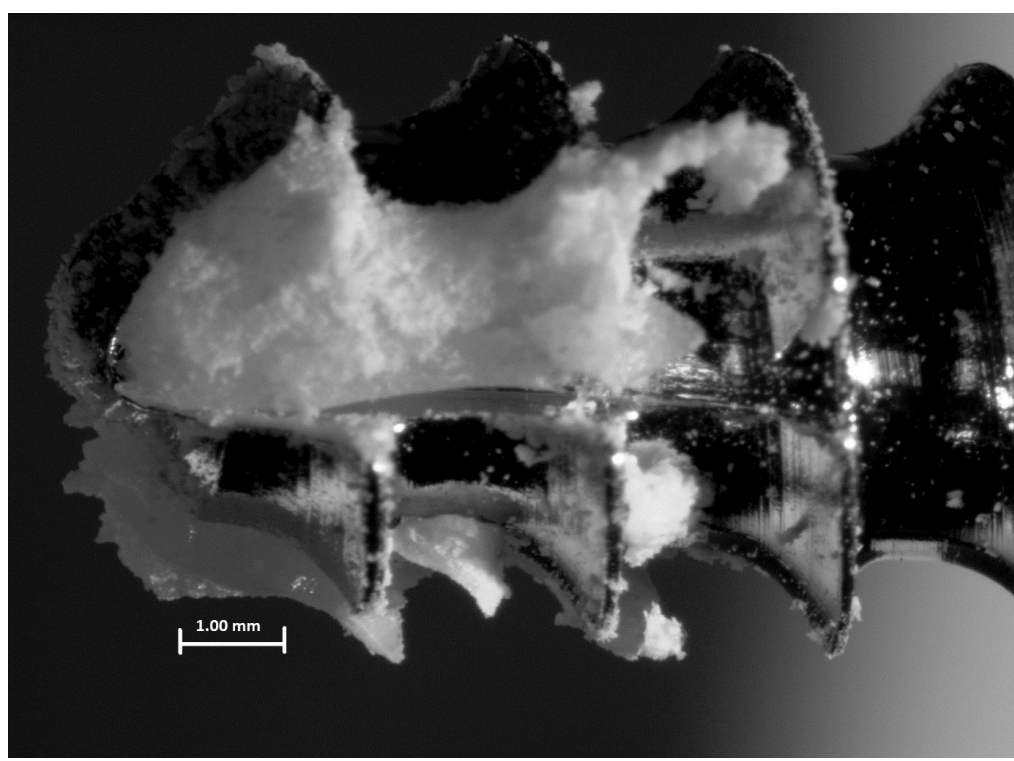

Figure 4. Photo of typical group B screw following removal with adherent cement in cutting flutes.

An explanation for the higher torque required for group B screw removal was found on closer examination of the flutes from screws removed. In group B screws, cement was adherent to the cutting flutes and it appeared to have fractured away from the cement mantle. Group A screws were retrieved with no adherent cement. It was noticed at time of testing that group B screws loosened with an audible "crack", while group A screws turned silently.

A limitation to this experiment was in modelling bone. In vivo when screws are advanced into bone they cause localised necrosis which over time remodels with closely apposed woven bone [8]. This model used a low viscosity cement which filled screw threads well but was unlikely to resemble exactly bone-screw interface. The modulus of cement is around $2 \mathrm{GPa}$ [9], one tenth that of cortical bone (20 GPa) [10] and one could theorise that actual removal torque would be higher in mature bone because of better bone-screw interface and higher modulus.

In vivo bone can grow over and cover plates sitting on the cortex and the same remodelling can occur at the periosteum and the tip of a screw that has penetrated the distal cortex of the bone. The bone formed could fill the cutting flutes. This in theory could lead to no benefit in terms of easier removal should a longer screw be utilised. To validate the model further research in animal and human tissue is needed. 
There will be risks associated with the application of these findings to clinical practice. It is not always possible to protrude screws through the distal cortex because this risks irritating soft tissues or damaging neurovascular structures. Results from this model also suggest that all cutting flutes need to be outside of the bone. To do this in practice requires the length of cutting flute to be known and the depth gauge altered to give the surgeon a screw length that ensures this.

Screw design plays an important role in its mode of failure. Having smaller cutting flutes would mean the possibility of less bony ingrowth and less resistance to removal. The metallurgist should also pay attention to torque strength of the head to the shaft of the screw, as well as ensuring that the head is strong enough to resist stripping.

\section{Conclusion}

Removal of metalwork following orthopaedic surgery is generally not required; however, in some cases, particularly in the paediatric population, removal is routine. The findings from this experiment may serve as a guide in pre-operative planning of metalwork removal as to which screws may be more difficult to remove.

\section{References}

[1] Canale, S. and Beaty, J. (2007) Campbell's Operative Orthopaedics. 11th Edition, Mosby/Elsevier, USA.

[2] Ansell, R. and Scales, J. (1968) A Study of Some Fractures Which Affect the Strength of Screws and Their Insertion and Holding Power in Bone. Journal of Biomechanics, 1, 279-302. http://dx.doi.org/10.1016/0021-9290(68)90023-7

[3] Baumgart, F.W., Morikawa, C.K., Morikawa, S.M., et al. (1993) AO/ASIF Self-Tapping Screws (STS). AO/ASIF Research Institute, Davos.

[4] Busam, M.L., Esther, R.J. and Obremskey, W.T. (2006) Hardware Removal: Indications and Expectations. Journal of the American Academy of Orthopaedic Surgeons, 14, 113-120.

[5] Jamil, W., Allami, M., Choudhury, M.Z., Mann, C., Bagga, T. and Roberts, A. (2008) Do Orthopaedic Surgeons Need a Policy on the Removal of Metalwork? A Descriptive National Survey of Practicing Surgeons in the United Kingdom. Injury International Journal of the Care of the Injured, 39, 362-367. http://dx.doi.org/10.1016/j.injury.2007.10.028

[6] Jago, E.R. and Hindley, C.J. (1998) The Removal of Metalwork in Children. Injury, 29, 439-441. http://dx.doi.org/10.1016/S0020-1383(98)00080-1

[7] Webb, J.A., Almaiyah, M., McVie, J. and Montgomery, R.J. (2008) Proximal Femoral Osteotomies in Children Using the Richards Hip Screw: Techniques, Outcome and Subsequent Removal. Journal of Children's Orthopaedics, 2, 417423. http://dx.doi.org/10.1007/s11832-008-0127-8

[8] Schatzker, J. (1995) Osseointegration of Metal. Canadian Journal of Surgery, 38, S49.

[9] Hanser, D. and Jensen, J.S. (1992) Additional Mechanical Tests of Bone Cements. Acta Orthopaedica Belgica, 58, 268-271.

[10] Rua, J.Y., Ashman, R.B. and Turner, C.H. (1993) Young’s Modulus of Trabecular and Cortical Bone Material: Ultrasonic and Microtensile Measurements. Journal of Biomechanics, 26, 111-119. http://dx.doi.org/10.1016/0021-9290(93)90042-D 
Scientific Research Publishing (SCIRP) is one of the largest Open Access journal publishers. It is currently publishing more than 200 open access, online, peer-reviewed journals covering a wide range of academic disciplines. SCIRP serves the worldwide academic communities and contributes to the progress and application of science with its publication.

Other selected journals from SCIRP are listed as below. Submit your manuscript to us via either submit@scirp.org or Online Submission Portal.
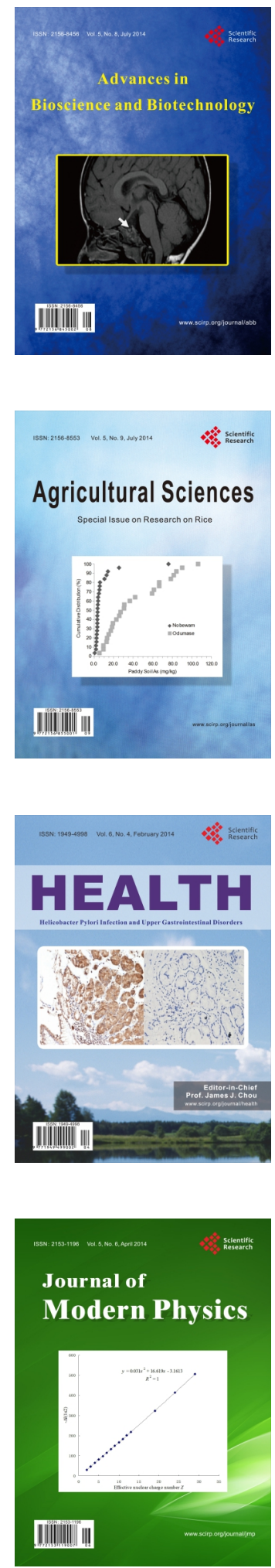
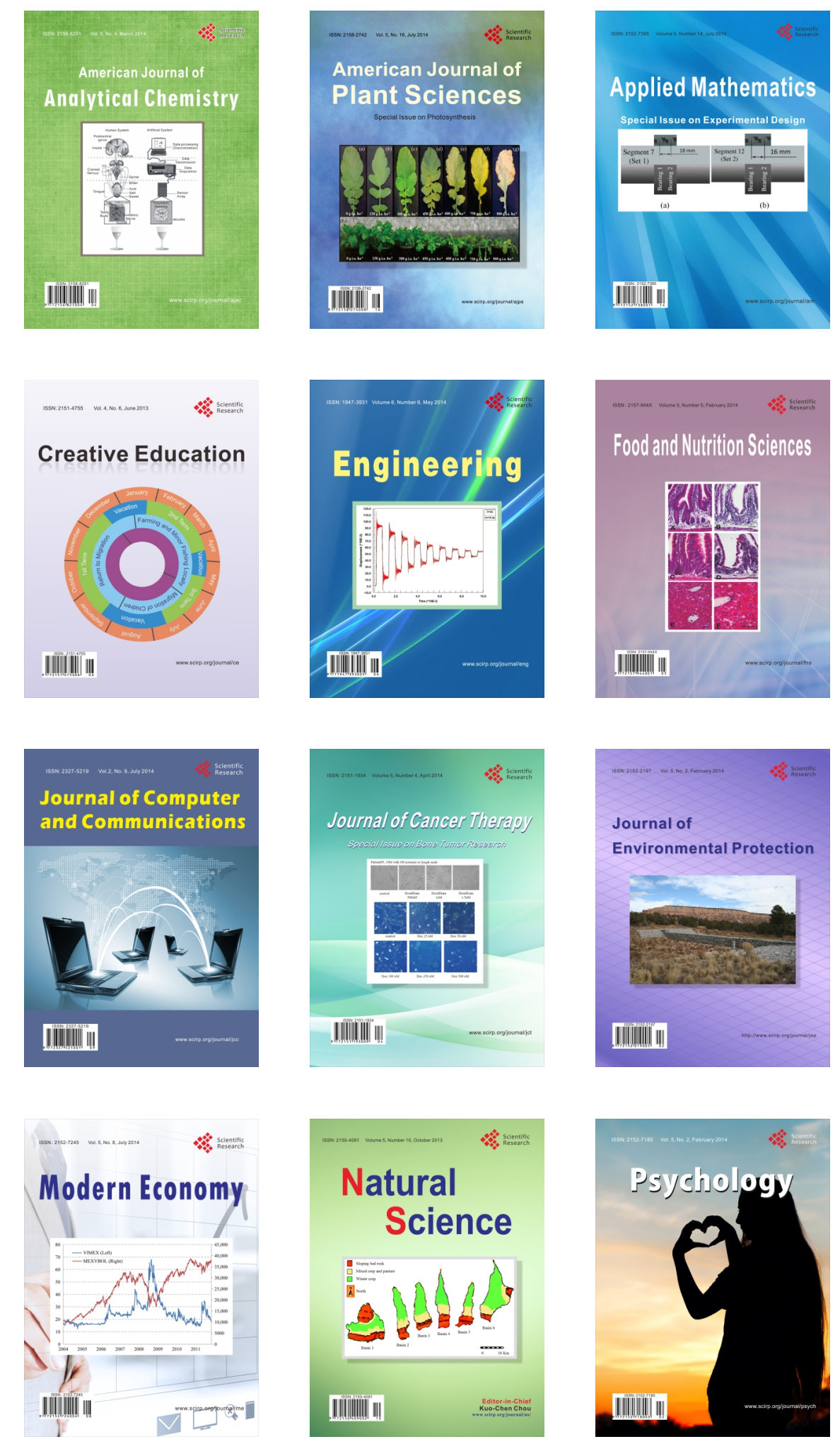